\title{
Existe-t-il un risque de transmission du virus du chikungunya au Canada?
}

\author{
Ogden N.H. ${ }^{{ }^{\star}}$, Lindsay L.R. ${ }^{2}$, Coulthart M. ${ }^{1}$ \\ ${ }^{1}$ Centre des maladies infectieuses d'origine alimentaire, environnementale et zoonotique, Agence de la santé publique du \\ Canada, Ottawa (Ontario) \\ ${ }^{2}$ Zoonoses et pathogènes spéciaux, Agence de la santé publique du Canada, Winnipeg (Manitoba) \\ *Auteur-ressource : Nicholas.ogden@phac-aspc.gc.ca
}

\section{Résumé}

Une éclosion des infections par le virus du chikungunya a lieu actuellement dans les Caraïbes, en Amérique centrale et en Amérique du Sud et une transmission autochtone (locale ou indigène) a été enregistrée dans le sud-est des États-Unis. Les espèces de moustiques qui transmettent le virus du chikungunya, Aedes aegypti et Aedes albopictus, ne semblent, pour l'heure, pas présentes au Canada. Mais comment être sûr que cette situation va perdurer? Dans le présent document, nous examinons quatre conditions principales qui doivent être réunies pour que le virus du chikungunya soit transmis au Canada. Nous concluons que toutes ces conditions ne sont pas réunies et qu'à l'heure actuelle, le risque de transmission du virus du chikungunya dans la majeure partie du Canada semble très faible. Le risque est légèrement plus élevé dans les régions plus chaudes, telles que le sud de la Colombie-Britannique, et dans les zones isolées du centre-sud et du sud-est du Canada. Nous ignorons toutefois beaucoup de choses et il est nécessaire de réaliser une évaluation continue des risques, de mener des recherches et d'effectuer une surveillance des vecteurs du virus du chikungunya.

\section{Introduction}

La maladie virale transmise par les moustiques, appelée chikungunya, est endémique dans certaines parties d'Afrique et d'Asie et sur des îles des océans Indien et Pacifique. En décembre 2013, deux cas de transmission autochtone (locale ou indigène) du virus du chikungunya dans l'île antillaise de Saint-Martin/Sint Maarten ont marqué le début de son éclosion dans l'hémisphère occidental. Pendant l'année 2014, le virus du chikungunya s'est propagé dans la majeure partie des Caraïbes, ainsi que dans certaines zones d'Amérique centrale, d'Amérique du Sud et du Mexique, et une transmission autochtone a été décelée dans le sud-est des États-Unis $(1,2)$.

On a récemment constaté une hausse rapide des diagnostics en laboratoire d'infections au virus du chikungunya contractées en voyage par des Canadiens (3). C'était prévisible, étant donné le grand nombre de Canadiens qui se rendent dans les régions touchées, pour affaires ou en vacances (3). Outre le danger direct de contracter des infections en voyage, quel est le risque que les voyageurs ayant contracté le virus à l'étranger rentrent et agissent comme source de transmission autochtone locale du virus du chikungunya au Canada? Dans le présent article, nous évaluons la possibilité de transmission locale du virus du chikungunya au Canada, qui pourrait conduire à des cas autochtones isolés ou à des éclosions.

\section{Analyse}

Quatre conditions doivent être réunies pour une transmission locale du virus du chikungunya : l'introduction du virus; la présence d'un vecteur compétent; des conditions climatiques propices à la transmission du virus; et un nombre suffisant de personnes réceptives. Nous examinons chacune de ces conditions ci-après et déterminons si elles sont actuellement présentes au Canada.

\section{Présentation du virus du chikungunya}

Les voyageurs, y compris les Canadiens, qui contractent le virus du chikungunya sont souvent virémiques à leur retour; ils pourraient être la source de l'infection de résidents canadiens, si des moustiques représentant des 
vecteurs compétents étaient présents et si d'autres conditions de transmission étaient réunies (3). Les voyageurs infectés et virémiques, qui rentrent de voyage, sont considérés comme la principale source de propagation du virus du chikungunya à travers le monde et la source d'introduction de l'infection la plus probable, ayant conduit à des éclosions en Italie, ainsi qu'à des cas autochtones en France et aux États-Unis $(4,5,6)$. Des moustiques infectés pourraient être introduits grâce au commerce international, par l'intermédiaire de produits transportant des moustiques infectés vivants depuis des régions touchées (4). Des études sont en cours afin de repérer d'éventuels points névralgiques au Canada, où l'introduction du virus du chikungunya serait possible grâce aux importations contaminées par les hommes ou les moustiques.

\section{Présence d'un vecteur compétent}

Pour que la transmission se fasse au Canada, d'un voyageur infecté qui rentre de voyage à un résident canadien réceptif, des moustiques d'une espèce capable de transmettre le virus doivent être présents. Les deux seuls vecteurs connus comme étant capables de transmettre le virus du chikungunya, et considérés comme ayant joué un rôle dans l'éclosion du virus, sont les moustiques Aedes aegypti (le moustique de la fièvre jaune) et Aedes albopictus (le moustique tigre asiatique) (2, 4). Le facteur déterminant principal de l'implantation de ces moustiques est le climat. Les deux espèces sont en cause dans la transmission du virus du chikungunya dans l'actuelle éclosion dans les Amériques (1).

Aedes aegypti est un moustique acclimaté aux régions subtropicales et tropicales. D'après nos conditions climatiques actuelles, et même en cas de changement climatique, il est peu probable qu'il s'implante au Canada (7). En revanche, le moustique Aedes albopictus peut survivre à des températures du nord plus fraîches. Il est capable de survivre à des hivers froids et s'est implanté dans certaines parties des États-Unis dans les années 1980 (8). Ce moustique apparaît désormais au centre et à l'est des États-Unis et s'étend au sud des États limitrophes du Canada, dont New York, la Pennsylvanie et l'Ohio. Il est également apparu dans plusieurs États de l'ouest, mais en a été éradiqué (8). Toutefois, nos connaissances actuelles des endroits où vit le moustique Aedes albopictus en Amérique du Nord reposent principalement sur une surveillance informelle et des études sur le terrain. Une surveillance, qui déterminerait si ce moustique s'installe dans des régions à risque du Canada et à quel endroit il le fait, est en cours de planification avec des partenaires provinciaux.

D'après les récentes études, le climat dans la majeure partie du Canada (à l'exception de la côte sud de la Colombie-Britannique et de quelques endroits au centre-sud et au sud-est du Canada) n'est pas propice à la survie à long terme du moustique Aedes albopictus (9). II existe quelques rares cas signalés de ce moustique au Canada (10), mais rien ne prouve qu'il s'est implanté dans notre pays. Cette situation pourrait évoluer en cas de changement climatique. Des recherches approfondies doivent être menées pour évaluer l'ampleur du changement nécessaire pour que les moustiques Aedes albopictus s'implantent (9).

\section{Présence de conditions climatiques propices}

Deux facteurs climatiques déterminent si les conditions sont propices à la transmission du virus du chikungunya. Premièrement, le climat doit permettre d'abriter non seulement les populations reproductrices des espèces de moustiques, mais également des populations dont l'abondance est suffisante pour qu'au moins un moustique contracte le virus du chikungunya d'une personne infectée et survive pour le transmettre à une personne non infectée. Deuxièmement, les températures doivent être suffisamment élevées pour que le virus du chikungunya se propage depuis l'intestin du moustique (où le virus apparaît d'abord, une fois contracté au contact d'une personne infectée) vers ses glandes salivaires (d'où le virus est transmis à la salive, lorsque le moustique va se nourrir), avant que le moustique ne meure. D'après de récentes études fondées sur les expériences passées, le seuil de température propice à l'éclosion du virus du chikungunya est fixé à $20^{\circ} \mathrm{C}(10)$. Nous enquêtons actuellement pour savoir où et quand les conditions climatiques sont propices à la transmission du virus du chikungunya au Canada, dans les conditions climatiques actuelles et futures. Afin d'améliorer notre évaluation des risques de transmission autochtone et de guider les programmes de santé publique, les résultats de ces recherches seront associés aux évaluations de l'endroit où des moustiques vecteurs à risque peuvent apparaître.

\section{Présence d'un nombre suffisant de personnes réceptives}

S'il existait des endroits au Canada où des moustiques compétents étaient implantés en nombre suffisant pour transmettre le virus, et qu'ils étaient exposés à des personnes infectées rentrées de pays touchés, des cas individuels de transmission autochtone du virus du chikungunya seraient possibles. Toutefois, pour que la 
transmission soit durable à court ou à long terme, les moustiques infectés devraient avoir accès à un nombre suffisant de personnes réceptives.

Dans les pays en développement, les moustiques accèdent relativement facilement aux bâtiments et aux personnes qui les occupent. Dans des pays comme le Canada, en revanche, la plupart des habitations et des entreprises sont bien isolées de l'incursion de moustiques et les piqûres de moustiques surviennent principalement lorsque les gens sont à l'extérieur. En général, cela ne touche pas de grandes foules, mais plutôt des randonneurs, des jardiniers et d'autres personnes en nombre relativement restreint. En l'absence d'un nombre suffisant d'êtres humains, les moustiques Aedes albopictus infectés se nourriraient plus probablement sur des animaux sauvages ou domestiques, empêchant ainsi la transmission aux êtres humains. On considère que ces facteurs socioéconomiques limitent la transmission d'autres maladies à transmission vectorielle, telles que la dengue, et qu'ils seront probablement un frein majeur à la transmission autochtone présumée du virus du chikungunya dans des pays tels que le Canada (11).

\section{Discussion et conclusion}

Étant donné l'actuelle éclosion du virus du chikungunya au sud de nos régions, dans les Amériques, il est nécessaire d'évaluer les risques de cas autochtones ou d'éclosion limitée du virus du chikungunya au Canada. À l'heure qu'il est, rien ne prouve que des vecteurs compétents du virus du chikungunya, tels que le moustique Aedes albopictus, soient implantés au Canada. En outre, les conditions climatiques semblent actuellement essentiellement inadaptées à cette espèce, ou sous-optimales. Par conséquent, le risque de cas autochtones et d'éclosion du virus du chikungunya au Canada apparaît actuellement très faible. Toutefois, ce risque est légèrement plus élevé dans les régions plus chaudes, telles que le sud de la Colombie-Britannique, et dans les zones isolées du centre-sud et du sud-est du Canada. En outre, les facteurs socioéconomiques peuvent aussi nuire à la transmission du virus de l'homme au moustique, puis du moustique à l'homme.

Le risque principal de transmission autochtone au Canada viendrait des moustiques Aedes albopictus s'ils s'implantaient ici. Ce que nous savons de ses allées et venues actuelles sont fondées sur une surveillance informelle. Des recherches complémentaires sur le terrain sont nécessaires en Amérique du Nord pour mieux comprendre et prédire les limites imposées par le climat à cette espèce (10).

Plusieurs facteurs pourraient modifier cette évaluation. En été, on atteint parfois les températures propices à la transmission du virus du chikungunya dans de nombreuses régions du Canada (9) et il est possible que, dans certaines circonstances, les conditions de logement et la densité des personnes non infectées soient suffisantes pour pérenniser des éclosions limitées. En outre, il est possible que, grâce à leur plasticité génétique, les espèces de moustiques puissent mieux survivre dans des climats plus frais et plus nordiques. II est toutefois difficile de le prédire (10). Enfin, des mutations virales pourraient théoriquement entraîner la transmission de virus par d'autres vecteurs implantés au Canada (2).

En conclusion, d'après nos observations, le risque actuel de propagation autochtone du virus du chikungunya au Canada est très faible, mais nous ignorons certains éléments et plusieurs facteurs pourraient modifier cette évaluation des risques. Il est donc nécessaire de mener une évaluation des risques continue, de prendre en compte les effets anticipés du changement climatique, de surveiller les cas humains de chikungunya, de procéder à une surveillance accrue des moustiques vecteurs et d'élaborer des plans de prévention et de contrôle des éclosions de ce virus et d'autres maladies vectorielles exotiques, qui pourraient menacer la santé de la population canadienne au cours des prochaines décennies.

\section{Remerciements}

Aucun

\section{Conflit d'intérêts}

Aucun 


\section{Financement}

Aucun

\section{Références}

(1) Pan American Health Organization. Number of reported cases of chikungunya fever in the Americas-EW 40 (October 24, 2014). http://www.paho.org/hq/index.php?option=com_topics\&view=article\&id=343\&ltemid=40931

(2) Powers AM. Risks to the Americas associated with the continued expansion of Chikungunya virus. J Gen Virol. 2014 pii: vir.0.070136-0.

(3) Drebot, MA, Holloway, K, Zheng, H, Ogden, NH. Cas de chikungunya liés aux voyages au Canada, 2014. Relevé des maladies transmissibles au Canada, 8 janvier 2015; 41(1):2-6. http://www.phac-aspc.gc.ca/publicat/ccdrrmtc/14vol41/index-fra.php

(4) Charrel RN, De Lamballerie X, Raoult D. Chikungunya outbreaks-The globalization of vectorborne diseases. N Engl J Med. 2007; 356:769-71.

(5) La Ruche G, Souarès Y, Armengaud A, Peloux-Petiot F, Delaunay P, Desprès P, et al. First two autochthonous dengue virus infections in metropolitan France. Euro Surveill. 2010; 15:19676.

(6) Johansson MA, Powers AM, Pesik N, Cohen NJ, Staples JE. Nowcasting the spread of chikungunya virus in the Americas. PLoS One. 2014; 9:e104915.

(7) Khormi HM, Kumar L. Climate change and the potential global distribution of Aedes aegypti: Spatial modelling using GIS and CLIMEX. Geospat Health. 2014; 8:405-15.

(8) Moore CG. Aedes albopictus in the United States: Current status and prospects for further spread. J Am Mosq Control Assoc. 1999; 15:221-7.

(9) Fischer D, Thomas SM, Suk JE, Sudre B, Hess A, Tjaden NB, et al. Climate change effects on Chikungunya transmission in Europe: Geospatial analysis of vector's climatic suitability and virus' temperature requirements. Int $\mathrm{J}$ Health Geogr. 2013; 12:51.

(10) Ogden NH, Radojevic M, Caminade C, Gachon P. Recent and projected future climatic suitability of North America for the Asian tiger mosquito Aedes albopictus. Parasites \& Vectors. 2014 Dec 2; 7:532.

(11) Reiter P. Climate change and mosquito-borne disease. Environ Health Perspect. 2001; 109(Suppl 1):141-61. 